\title{
Simultaneous Estimation of Racecadotril and Ofloxacin by Reverse Phase High Performance Liquid Chromatography Method in Pharmaceutical Dosage Forms.
}

\author{
Gupta Komal, Sharma Deepika, Chawla Pooja* \\ Department of Pharmaceutical Analysis, ISF College of Pharmacy, Moga-142001, India
}

\begin{abstract}
Background: Racecadotril and Ofloxacin (RACIGYL- 0) drug combination are used for the treatment of diarrhea. The drugs have been estimated individually in formulations but no method has been developed for simultaneous estimation of these two drugs as combination.

objective: To develop and validate a high performance liquid chromatography method for the simultaneous estimation of Racecadotril and Ofloxacin in tablet dosage form.

Method: A WATERS $\mathrm{C}_{18}$ column $(250 \times 4.6 \mathrm{~mm}, 5 \mu \mathrm{m})$ with mobile phase consisting of acetonitrile, methanol and water $40: 40: 20 \mathrm{v} / \mathrm{v}(\mathrm{pH}$ adjusted to 2.7 of water with ortho phosphoric acid). The flow rate was $1.0 \mathrm{~mL} / \mathrm{min}$ and effluents were monitored at $210 \mathrm{~nm}$.

Results: The retention time of RAC and OFL was $4.666 \mathrm{~min}$ and $2.551 \mathrm{~min}$ respectively. The developed method was validated according to I CH guidelines with respect to specificity, linearity, accuracy, precision, robustness, Limit of Detection (LOD) and Limit of Quantification (LOQ).

Conclusion: The method show good reproducibility and recovery with \%RSD less than 2 . So the proposed method was found to be simple, rapid, precise and accurate and useful for the determination of RAC and OFL in bulk and pharmaceutical dosage forms.
\end{abstract}

Keywords: RP-HPLC, Racecadotril, Ofloxacin, ICH guidelines.

Article Info: Received 07 June 2019; $\quad$ Review Completed 14 July 2019; $\quad$ Accepted 20 July $2019 ; \quad$ Available online 15 August 2019

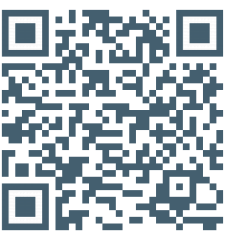

Cite this article as:

Gupta K, Sharma D, Chawla P, Simultaneous Estimation of Racecadotril and Ofloxacin by Reverse Phase High Performance Liquid Chromatography Method in Pharmaceutical Dosage Forms., Journal of Drug Delivery and Therapeutics. 2019; 9(4s):165-170 http://dx.doi.org/10.22270/jddt.v9i4-s.3266

*Address for Correspondence:

Dr. Pooja Chawla, Professor, Department of Analysis and Pharmaceutical Chemistry, Indo Soviet Friendship College of Pharmacy, Moga-142001, Punjab, India

\section{INTRODUCTION}

Combined dosage forms are mostly preferred these days as compared to single dosage forms. Racecadotril and ofloxacin is available in combined pharmaceutical dosage form. The brand name is Racigyl- 0 tab containing $100 \mathrm{mg}$ of racecadotril and $200 \mathrm{mg}$ of ofloxacin used in the treatment of diarrhea1. Literature survey reveals that various analytical methods have been reported for single dosage forms. The present paper aims to report a simple, accurate, precise, RPHPLC method for estimation of racecadotril and ofloxacin in combined dosage forms.

\subsection{Drug profile of Racecadotril}

It is chemically known as $\mathrm{N}$-[2-[(acetylthio)methyl]-1-oco-3phenyl-propanoyl)-glycine phenylmethyl ester, which is a prodrug of the enkephalinase inhibitor thiorphan ${ }^{2}$.It is a white powder and freely soluble in methanol and in dichloromethane and practically insoluble in water ${ }^{3}$.<smiles>CC(=O)SCC(Cc1ccccc1)C(=O)NCC(=O)OCc1ccccc1</smiles>

Racecadotril

Fig.1. Structure ofRacecadotril ${ }^{2}$ 
1.2 Drug profile of Ofloxacin<smiles>CC(C)OC(=O)c1cn2c3c(c(N4CCN(C)CC4)c(F)cc3c1=O)OCC2C</smiles>

Fig. 2.Structure of Ofloxacin

It is a $( \pm)-9$-fluoro-3-methyl-10-(4-methylpiperazin-1-yl)-7oxo-2,3-dihydro-7 H-pyridol(1,2,3,-de)-1,4-benzoxazine-6carboxylic acid 4 and it is a synthetic broad spectrum antibacterial agent which is official in USP and BP5. It acts on DNA gyrase and topoisomerase IV and prevents the excessive supercoiling of DNA during transcription and translation and by inhibiting their function, it inhibits the normal cell divison ${ }^{6}$. It is a pale yellow or bright yellow crystalline powder 6 and it is soluble in glacial acetic acid, and slightly soluble in water, dichloromethane and methanol ${ }^{3}$.

\section{MATERIALS AND METHODS}

\subsection{Optimized chromatographic conditions}

Suitable high performance liquid chromatography equipped with UV-visible detector was used. HPLC (waters, 2695 separation module) SOFTWARE (Empower, version 2.0)

Column: Waters C18, 50mm x 4.6

Wavelength: $210 \mathrm{~nm}$

Injection Volume: $10 \mu \mathrm{L}$

Column Temperature: Ambient

Flow Rate: $1.0 \mathrm{~mL} / \mathrm{min}$

Retention time of Racecadotril and Ofloxacin are 4.666 and 2.551 min respectively.

\subsection{Chemicals and Reagents}

Racecadotril and ofloxacin were received as gift sample from Leeford Healthcare Pvt. Ltd. Ludhiana and Tanishka Pharmaceuticals Pvt. Ltd. Baddi. The pharmaceutical preparations of combination of racecadotril and ofloxacin that is RACIGYL-O tablets (Mankind) contains $100 \mathrm{mg}$ of racecadotril and $200 \mathrm{mg}$ of ofloxacin was procured from local market. The solvents used for method development and validation were Methanol AR Grade, HPLC grade Methanol (S.D fine chemicals ltd, Mumbai, India), HPLC grade Acetonitrile and water for HPLC (Finar Chemicals Ltd., Mumbai, India).

\section{RP-HPLC method}

HPLC system of WATERS (Milford, USA) composed of 515 HPLC pump as a solvent delivery system equipped with Rheodyne injection valve with a $50 \mu \mathrm{L}$ loop. The chromatographic separation was performed with a WATERS, 2695 separation module HPLC instrument equipped with UV-VISIBLE detector and Empower software, version 2.0. The Waters $X$ bridge Stainless steel $\mathrm{C}_{18}$ column $(250 \mathrm{~mm}$ $\times 4.6 \mathrm{~mm}, 5 \mu \mathrm{m}$ ) packed with ODS chemically bounded porous silica particles were used as stationary phase for analysis. BL-220H analytical balance (Shimadzu corporation, Japan), an ultrasonic cleaner (Frontline FS 4, Mumbai, India) and
Digital pH meter (LI $612 \mathrm{pH}$ analyzer, Elico Ltd., Ahmadabad), were used in the study.

\subsection{Chromatographic condition}

The optimal composition of the mobile phase was determined to be acetonitrile, methanol and water $\mathrm{pH} 2.7$ maintained by ortho-phosphoric acid in the ratio (40:40:20 $\mathrm{v} / \mathrm{v}$ ). The mobile phase was filtered through nylon $0.22 \mu \mathrm{m}$ membrane filters and was degassed to remove the air before use (30 min). Stock solution was prepared by dissolving RAC and OFL (50 mg each) that were weighed accurately and separately transferred into $25 \mathrm{~mL}$ volumetric flasks. All the drugs were dissolved in $25 \mathrm{~mL}$ of mobile phase to prepare standard stock solutions. After the immediate dissolution, the solution was sonicated and made up the volume with mobile phase. These standard stock solutions were observed to contain $2000 \mathrm{mcg} / \mathrm{mL}$ of RAC and OFL. Appropriate volume from this solution was further diluted to get appropriate concentration levels according to the requirement. From the stock solutions, dilutions were made in the concentration range of $60,80,100,120,140 \mu \mathrm{g} / \mathrm{mL}$ for RAC and 120, 160, 200, 240, 280 $\mu \mathrm{g} / \mathrm{mL}$ for OFL.

\subsection{Preparation of mobile phase}

Mobile phase was prepared by mixing acetonitrile (HPLC grade), methanol (HPLC grade) and HPLC water $\mathrm{pH} 2.7$ $(40: 40: 20 \mathrm{v} / \mathrm{v})$. Mixture was shaken vigorously and sonicated for $30 \mathrm{~min}$ prior to use.

\subsection{Preparation of stock solutions}

Stock solutions and sample solutions of RAC and OFL and its binary mixture were prepared by adding accurately weighed $50 \mathrm{mg}$ of RAC and OFL separately in $25 \mathrm{~mL}$ volumetric flask containing $15 \mathrm{~mL}$ of mobile phase. The flasks were then sonicated for $10 \mathrm{~min}$ and the volume was made up to the mark by using mobile phase. These standard stock solutions were containing $2000 \mu \mathrm{g} / \mathrm{mL}$ of RAC and OFL. Stock solutions were used to prepare desired concentration range as per sample calibration range.

\subsection{Preparation of Sample solutions}

Twenty tablets were weighed and emptied. The equivalent weight was calculated and according to average weight, required drug was taken in volumetric flask to obtain $100 \mathrm{mg}$ of RAC and $200 \mathrm{mg}$ of OFL in single dilution i.e. according to the label claim of the formulation. The dilutions were first sonicated and then filtered through 0.22 micron filter paper.

\subsection{Preparation of Calibration curve}

The test concentrations for RAC and OFL in HPLC method development were found to be $100 \mu \mathrm{g} / \mathrm{mL}$ and $200 \mu \mathrm{g} / \mathrm{mL}$ respectively. The calibration curve was prepared by injecting the concentrations of $60-140 \mu \mathrm{g} / \mathrm{mL}$ of RAC and $120-280 \mu \mathrm{g} / \mathrm{mL}$ of OFL in mixture solution manually in triplicate to the HPLC system at detection wavelength of 210 $\mathrm{nm}$. Mean of $n=5$ determinations was plotted as the standard curve. The calibration curve was tested by validating it with inter-day and intra-day measurements. Linearity, accuracy and precision were performed for both inter-day and intraday measurements.

\section{Method validation}

\subsection{Linearity}

The methods were validated according to International Conference on Harmonization Q2B guidelines (2005) for validation of analytical procedures to determine the linearity, sensitivity, precision and accuracy for each analyte. 
Calibration curves were generated with appropriate volumes of working standard solutions for HPLC.

For HPLC assay method validation, the test concentrations were found to be $100 \mu \mathrm{g} / \mathrm{mL}$ of RAC and $200 \mu \mathrm{g} / \mathrm{mL}$ of OFL. Linearity of the proposed method was carried out by the preparation of $60 \%, 80 \%, 100 \%, 120 \%$ and $140 \%$ of RAC and OFL test concentration i.e.60, 80, 100, 120,140 $\mu \mathrm{g} / \mathrm{mL}$ for RAC and 120, 160, 200, 240, $280 \mu \mathrm{g} / \mathrm{mL}$ for OFL. The linearity was evaluated by the least square regression method using weight data.

\subsection{Precision and accuracy}

Both precision and accuracy were determined with standard quality control samples (in addition to calibration standards) prepared in triplicates at different concentration levels covering the entire linearity range. Precision is defined as a degree of repeatability of an analytical method under normal operational conditions. The precision of the assay was determined by repeatability (intra-day) and intermediate precision (interday) and reported as \%R.S.D. for a statistically significant number of replicate measurements. The intermediate precision was carried out by comparing the assays on 3 different days and the results documented as standard deviation and \%R.S.D ${ }^{7}$.

Accuracy is the percent of analyte recovered by assay from a known added amount. For the measurement of accuracy, data from nine determinations over three concentration levels covering the specified range were determined. The samples containing $80 \%, 100 \%$, and $120 \%$ of test concentrations were spiked with $100 \%$ of standard solution in HPLC and percentage recovery was calculated8.

\subsection{LOD and LOQ}

The limit of detection (LOD) is defined as the lowest concentration of an analyte that an analytical process can reliably differentiate from background levels. The limit of quantification (LOQ) is the lowest concentration of the standard curve that can be measured with acceptable accuracy, precision and variability 9 .

The LOD and LOQ were calculated as

$\mathrm{LOD}=3.3 \sigma / \mathrm{S}$

$\mathrm{LOQ}=10 \sigma / \mathrm{S}$
Where $\sigma$ is the standard deviation of the lowest standard concentration and $\mathrm{S}$ is the slope of the standard curve.

\subsection{Stability}

The stability of RAC and OFL in mobile phase was assessed by analyzing the sample concentrations at $1 \mathrm{~h}, 4 \mathrm{~h}, 9 \mathrm{~h}, 24 \mathrm{~h}$, $48 \mathrm{~h}$ and $60 \mathrm{~h}$. The concentrations used in this study were $100 \mu \mathrm{g} / \mathrm{mL}$ for RAC and $200 \mu \mathrm{g} / \mathrm{mL}$ for OFL prepared from stock solution of pure form and powdered tablet sample, respectively. Six replicate samples for each concentration were assayed at each time point. The stability was tested over a period of three days at room temperature.

\subsection{Robustness}

The effect of intentional variation in analytical conditions such as detection wavelength, mobile phase flow rate and mobile phase composition on the retention time and peak area was investigated one by one.

\section{Analysis of marketed tablets formulation by HPLC}

For the assay estimation of marketed formulation by HPLC, Weighed 10 tablets. Accurately weighed powder sample equivalent to $100 \mathrm{mg}$ of $\mathrm{RAC}$ and $200 \mathrm{mg}$ of OFL was dissolved in a $100 \mathrm{~mL}$ volumetric flask containing mobile phase. The solution was kept for sonication for $20 \mathrm{~min}$, filtered through Whatmann filter paper No. 41. Aliquot of this solution was diluted to produce the concentration of $100 \mu \mathrm{g} / \mathrm{mL}$ for RAC and $200 \mu \mathrm{g} / \mathrm{mL}$ for OFL. $(\mathrm{n}=6)$.

\section{RESULTS AND DISCUSSION}

RP-HPLC spectrophotometric methods were developed for RAC and OFL which can be conveniently employed for routine analysis in pharmaceutical dosage forms and will eliminate unnecessary tedious sample preparations. The chromatographic conditions were optimized in order to provide a good performance of the assay. The retention time of RAC and OFL in tablets formulation were found to be $2.551 \mathrm{~min}$ and $4.666 \mathrm{~min}$ respectively. The chromatograms have been shown in (Fig3 (a)). Various system suitability parameters are shown in Table 1. A five point calibration curve was constructed with working standards and was found linear $\left(r^{2} \geq 0.998\right.$ and 0.997$)$ for RAC and OFL over their calibration ranges. The slopes were calculated using the plot of drug concentration versus area of the chromatogram. The developed HPLC method was accurate, precise, reproducible and very sensitive shown in fig (3). 


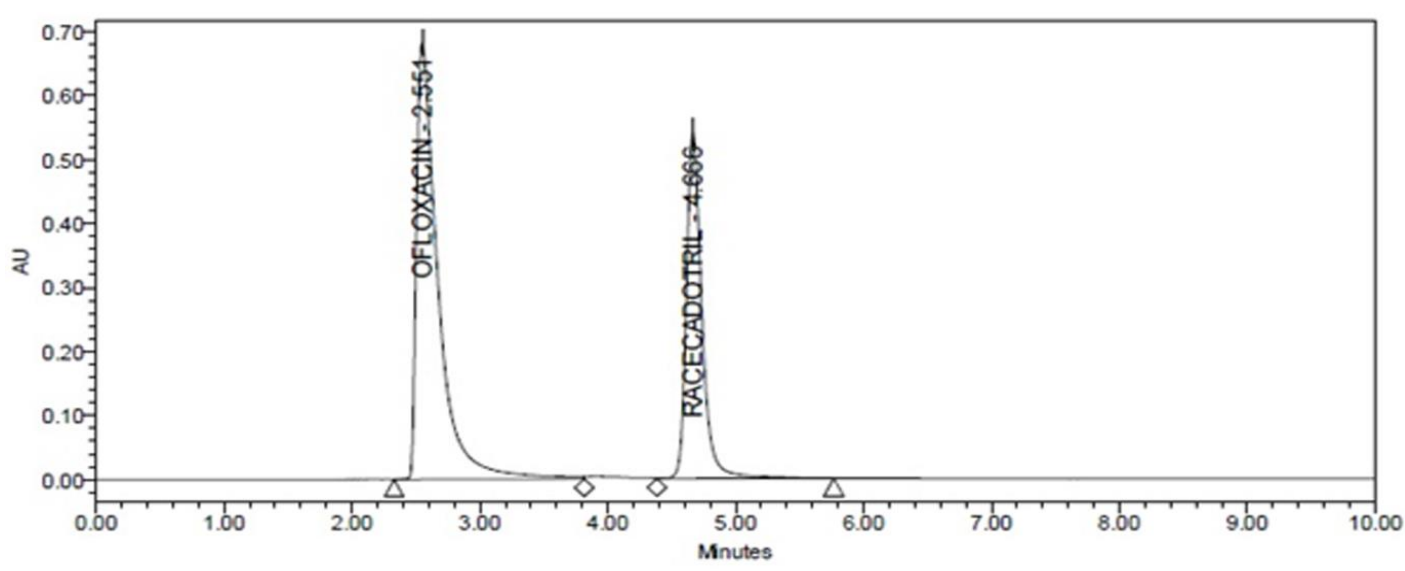

(a) Chromatogram of RAC and OFL

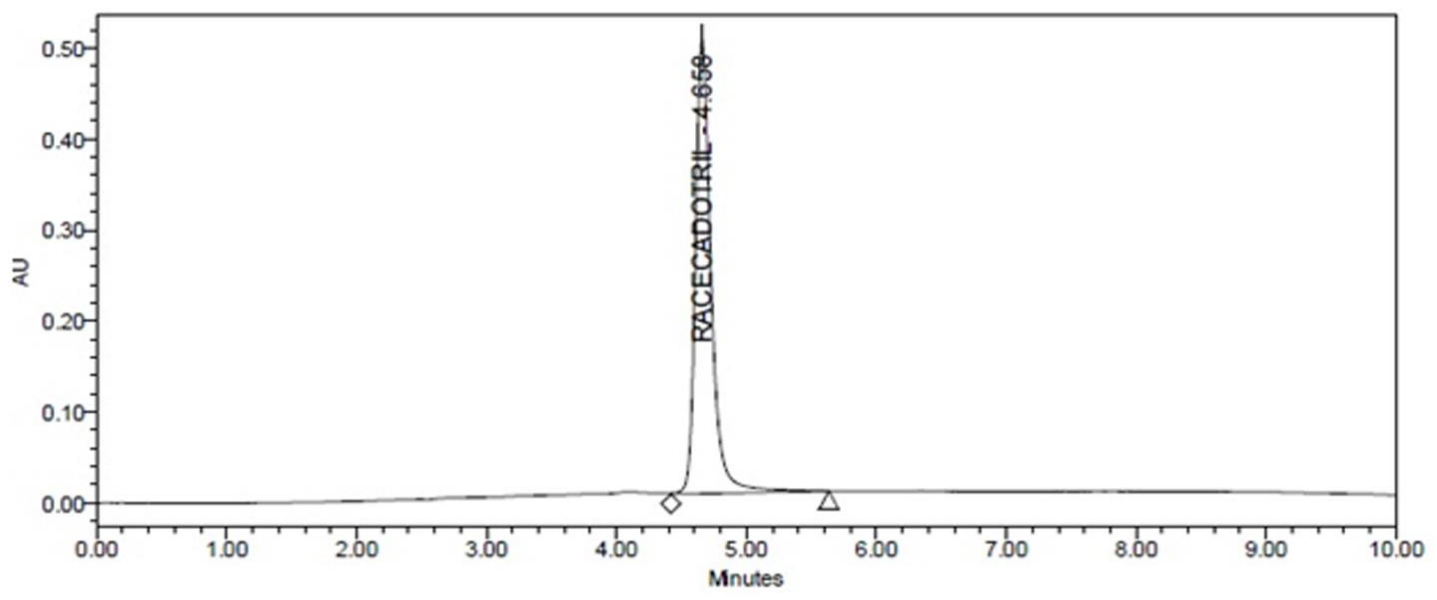

(b) Chromatogram of RAC at test concentration

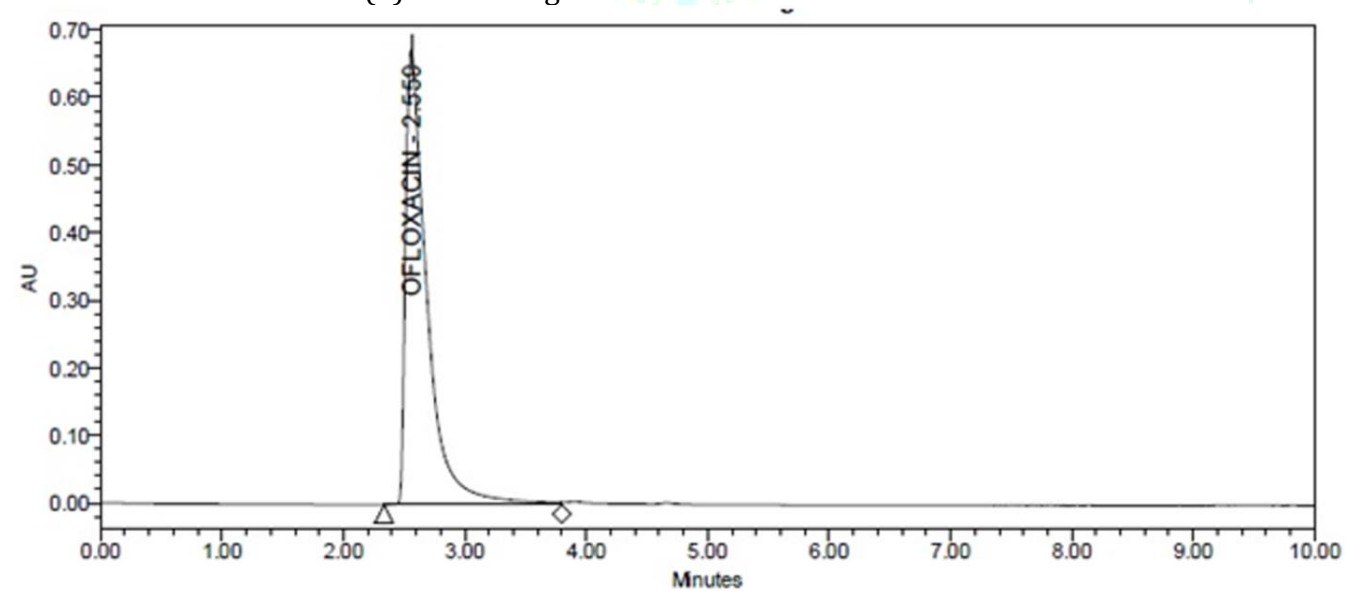

(c) Chromatogram of OFL at test concentration

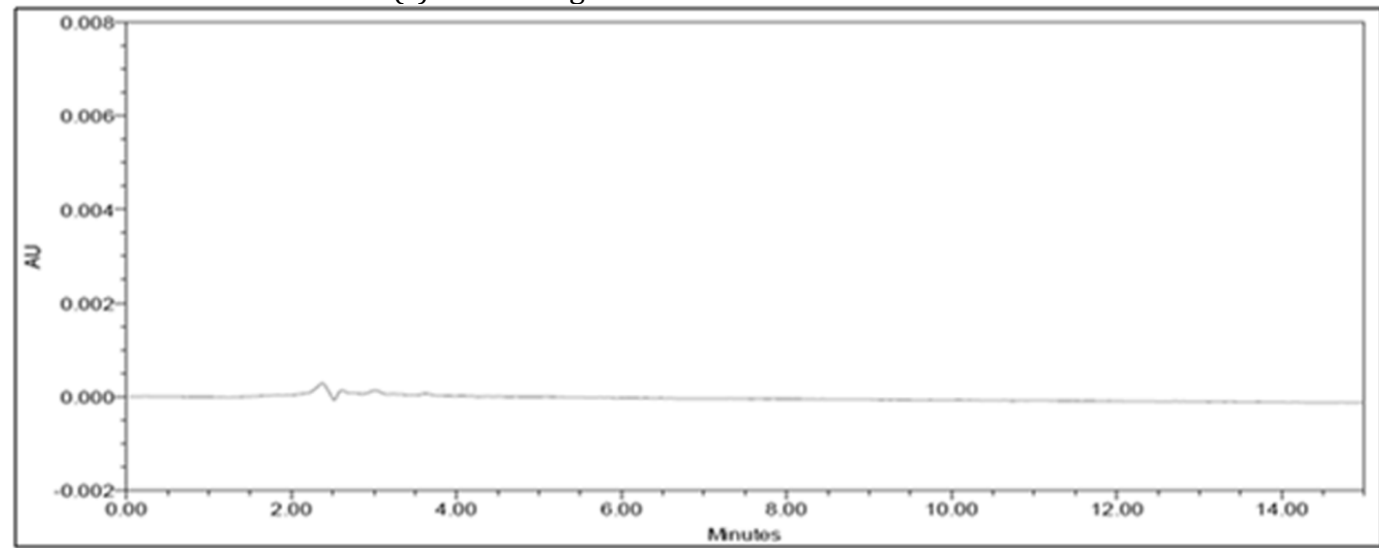

(d) Chromatogram of Blank

Fig.3. (a) Chromatograms of RAC and OFL (b) Chromatogram of RAC at test concentration (c) Chromatogram of OFL at test concentration (d) Chromatogram of Blank 
Table 1. System suitability studies of RAC and OFL in optimized RP-HPLC compared with USP pharmacopoeia limits.

\begin{tabular}{llcll}
\hline S.No & Parameters & USP Limit & RAC & OFL \\
1. & Conc. (\%) & - & $100 \%$ & $100 \%$ \\
2. & Retention time & - & 4.706 & 2.592 \\
3. & Average peak area of 6 injection & - & 4541354.5 & 7830038 \\
4. & \% RSD of peak area of 6 injections & $\leq 2.0$ & 0.2008 & 0.480 \\
5. & Peak Asymmetry (at 10\% peak height) & $\leq 1.5$ & 1.13 & 1.39 \\
6. & Mean number of Theoretical plate & $\geq 2000$ & 2689 & 2414 \\
7. & Final retention time & - & 4.666 & 2.551 \\
\hline
\end{tabular}

All the method validation parameters are well within the limits as specified in the ICH Q2B guidelines as shown in Table $\mathbf{2}$ and Table $\mathbf{3}$ lists the percent recovery (content uniformity) of all the drugs in the commercial formulations by HPLC methods. Moreover the \%R.S.D. (less variation) shows good precision of both developed methods. The calculated LOQ and LOD concentrations confirmed that the methods were sufficiently sensitive. The methods were suitably employed for assaying all the drugs in commercial marketed formulation (Table 4).

Table 2. Summary of the HPLC method validation

\begin{tabular}{llll}
\hline S.No & Validation parameter & RAC & OFL \\
1. & Absorption maxima, $\chi_{\max }(\mathrm{nm})$ & 210 & 210 \\
2. & Linearity range $(\mu \mathrm{g} / \mathrm{mL})$ & $60-140$ & $120-280$ \\
3. & Coefficient of determination $\left(\mathrm{R}^{2}\right)$ & 0.9989 & 0.9976 \\
4. & Regression equation $(\mathrm{y})$ & $\mathrm{y}=43570 \mathrm{x}+173113$ & $\mathrm{y}=76743 \mathrm{x}+77056$ \\
5. & Slope $(\mathrm{b})$ & 43570 & 76743 \\
6. & Intercept $(\mathrm{a})$ & 173113 & 77056 \\
7. & Limit of detection $(\mu \mathrm{g} / \mathrm{mL})$ & 3.56 & 3.10 \\
8. & Limit of quantification $(\mu \mathrm{g} / \mathrm{mL})$ & 10.78 & 9.41 \\
9. & Precision $(\% \mathrm{RSD})$ & Intraday=0.2008 & Intraday=0.164 \\
& & Interday=0.976 & Interday=0.834 \\
10. & Solution stability & Stable up to 24 hours & Stable up to 24 hours \\
& $>12$ hours & $\% \mathrm{RSD}=0.653$ & $\%$ RSD $=0.756$ \\
11. & Robustness (\%RSD) & complies & Complies \\
& Flow plus & 0.350 & 0.103 \\
& Flow minus & 0.338 & 0.207 \\
& Organic plus & 0.273 & 0.107 \\
& Organic minus & 0.364 & 0.279 \\
& Wavelength plus & 0.220 & 0.116 \\
& Wavelength minus & 0.146 & 0.199 \\
\hline
\end{tabular}

Table 3. Results of recovery study by HPLC methods.

\begin{tabular}{cllll}
\hline Method & Drug & Amt. present $(\boldsymbol{\mu g} / \mathbf{m L})$ & Amt. spiked $(\boldsymbol{\mu g} / \mathbf{m L})$ & \% Recovery* \\
HPLC & RAC & 80 & 100 & 99.99 \\
method & & 100 & 100 & 100.00 \\
& & 120 & 100 & 100.2 \\
& OFL & 160 & 200 & 99.42 \\
& & 200 & 200 & 100.6 \\
& & 240 & 200 & 100.64 \\
\hline
\end{tabular}

Table 4. Assay of marketed formulation RACIGYL-O by HPLC methods

\begin{tabular}{llll}
\hline Drug & Label claim (mg) & Amount found (mg) & \%Assay \\
RAC & 100 & 100.009 & 100.02 \\
OFL & 200 & 200.012 & 100.12 \\
\hline
\end{tabular}




\section{CONCLUSION}

Simple, rapid, accurate and precise RP-HPLC methods have been developed and validated for the routine analysis of RAC and OFL in API and capsules dosage forms. The methods are suitable for the simultaneous determination of RAC and OFL in multi-component formulations without interference of each other. The developed methods are suggested for routine and quality control analysis of the investigated drugs in pharmaceutical preparations. The amount found from the proposed methods was in good conformity with the label claim of the formulation. Also the value of standard deviation and coefficient of variation calculated were acceptably low, indicating the suitability of the proposed methods for the routine estimation of tablets dosage forms.

\section{CONFLICT OF INTEREST}

The authors confirm that this article content has no conflict of interest.

\section{REFERENCES}

[1] Racigyl 0 Tablets: Uses, Price, Side Effects, Composition, Substitutes, Precautions and Advice-Mankind Pharma $\begin{array}{lllll}\text { Ltd|strip } & \text { of } & 10 & \text { tablets. } & 1 \mathrm{mg}\end{array}$ https://www.1 mg.com/drugs/racigyl-o-100mg-200mgtablet-394115-149373 (accessed May 01, 2019).
[2] Laha TK, Patnaik R, Choudhury S, Sen S, Reverse phase high performance liquid chromatographic method for the analysis of Racecadotril in pharmaceutical dosage forms, Asian J Chem. 2008; 20:2575-2579.

[3] Indian Pharmacopoeia, Vol I, Controller of Publication, Delhi, 2.4.26 Solubility, 2014

[4] Patel DM, Soneji JA, Patel PB, Patel C, Development and validation of a method for simultaneous estimation of ofloxacin and ornidazole in different dissolution media, Pharm Methods. 2012; 3:102-105.

[5] Dhandapani B, Thirumoorthy N, Rasheed SH, Kotaiah MR, Anjaneyalu N., Method development and validation for the simultaneous estimation of ofloxacin and ornidazole in tablet dosage form by RP-HPLC, Int J Pharma Sci. 2010; 1(1):78-83.

[6] Drew RH, Gallis HA, Ofloxacin: its pharmacology, pharmacokinetics, and potential for clinical applications, Pharmacotherapy. 1988; 8:35-46.

[7] Swartz ME, Krull IS, Analytical method development and validation, J. Am. Chem. Soc . 1997; 22:104-119.

[8] Ahuja S, Rasmusssen H, HPLC method development for pharmaceuticals, First ed., Elsevier. 1997; 6:145-186.

[9] International conference on harmonization of technical requirements for registration of pharmaceuticals for human use ICH harmonized Tripartite Guideline on Validation of Analytical procedures: Text and Methodology Q2 R(1). 